\title{
BRAIN GAME - DANÇA, DIFERENÇA E IDENTIDADE - DESCOBRINDO UMA NOVA EU DANÇA EM POSSIBILIDADES SOMÁTICAS
}

\section{Resumo}

O trabalho apresenta relações entre dança, diferença e identidade, a partir das vivências de uma das autoras com o sofrimento de um acidente vascular cerebral. Sempre relacionando a teoria à prática, as autoras oferecem um olhar crítico sobre uma formação em dança predominantemente clássica. O relato de retorno de uma das autoras aos palcos através da participação em trabalhos de dança contemporânea permeados por uma abordagem somática, principalmente nos métodos ideokinesis e Feldenkrais permite uma série de reflexões sobre dança e diferença na contemporaneidade, métodos de ensino, formas e marcas corporais ou mentais ocasionadas por modelos advindos do ballet.

Palvras-chave: Ballet, Contemporaneidade, Educação Somática, Diferença

\section{Silvia Susana Wolff* Julia Ziviani Vitiello**}

\begin{abstract}
The work presents relations among dance, difference and identity taking the experience of one of the authors with the suffering of a stroke as a starting point. Relating theory with practice, the authors offer a critical view on the predominantly classical education in dance. The report $f$ the return of one of the authors to the stage through the participation in contemporary dance works permeated by a somatic approach, mainly in ideokinesis and Feldenkrais methods allows a series of reflections on dance and difference in contemporaneity, teaching methods, body and mental marcs left by models originated in ballet.
\end{abstract}

Key-words: Ballet, Contemporaneity, Somatic Education, Difference.

\footnotetext{
* Doutora em Artes pela Universidade Estadual de Campinas. Professora Adjunta da Universidade Federal de Santa Maria (UFSM). Santa Maria.RS. Brasil. E-mail: silviawolff@uol.com.br

** Doutora em Educação pela Universidade Estadual de Campinas. Professora Adjunta da Universidade Estadual de Campinas. Programa de Pós Graduação em Artes da Cena. Campinas, SP, Brasil.
} 
Este texto versa sobre a forma como se ampliou a visão de uma das autoras* sobre dança após a experiência de uma Acidente Vascular Cerebral. Em face às radicais mudanças corporais sofridas recentemente, muitas questões passaram a inquietar as pesquisadoras e artistas criadoras. Como a formação em dança, especificamente com a técnica do ballet, poderiam ajudar no resgate e na construção de um novo corpo a partir do AVC? É possível se apoiar na percepção corporal adquirida através destes anos de formação e treinamento em dança? $A$ dança é reconhecida como a arte da comunicação do indivíduo consigo mesmo e com o outro, logo o que a dança pode significar e qual lugar ou função ocupa na sociedade? A partir deste novo corpo, lembrando e procurando por meio da memória sensorial sentir antigas conexões já estabelecidas pela dança antes da hemorragia cerebral, será possível reconhecer as possíveis contribuições dos métodos de Educação Somática neste processo? Neste caso como estes podem influenciar na prática e ensino do ballet, de modo que se possa transmitir diferentemente esta técnica a outros? Quais as possibilidades de trânsito entre a Dança e a Reabilitação? As mudanças vividas no corpo a partir do AVC trazem um modo diferenciado de pensar a dança, e como este fato pode auxiliar na busca por uma dança que contribua para a discussão de questões relativas a diversidade e identidade em processos de criação em dança?

Estas questões abrangem um espectro amplo do trabalho corporal em relação tanto ao indivíduo quanto à sua atuação artística. Vemos este texto como uma tentativa de compreender e estabelecer uma relação entre princípios da Educação Somática** através, principalmente, do trabalho de imagem desenvolvido no método de Ideokinesis, um dos métodos mais antigos para estudo do corpo-mente originados no mundo ocidental, que oferece uma prática baseada na imaginação, no toque sutil e na sinestesia de imagens específicas utilizadas para melhorar o movimento e a postura (BERNARD, 2006). Mabel Todd foi a primeira a conceber e ensinar este método. (TODD, 1937). Sua aluna Lulu Sweigard foi instrumental em fazer a Ideokinesis ficar amplamente conhecida tanto através de seus ensinamentos quanto através de seu livro Human movement potential (1974). Podemos citar outros alunos de Todd que também colaboraram na pesquisa e desenvolvimento do método como Bárbara Clark, Pamela Matt, Irene Dowd, Nancy Topf e André Bernard entre outros. Este método foi vivenciado pelas autoras como mestrandas do programa de pós-graduação do departamento de dança do Tisch School of the Arts da New York University. Outra técnica somática que abordaremos, por trazer questões relacionadas à autoimagem e movimento, é a de Moshe Feldenkrais, também vivenciada pelas autoras.

A trajetória de retorno de Autora A à dança veio a ser efetivada se efetivou através do encontro com a coreógrafa suíça Anna Rothlisberger, uma instrutora de Feldenkrais que estava à procura de uma bailarina que possuísse uma deficiência física e um histórico profissional na dança. Este encontro deu-se em função de seu desejo de se aproximar, novamente, da arte da dança e através de contatos e pesquisas sobre a cena independente da dança contemporânea na Suíça, onde desenvolvia um projeto para uso da dança como método de reabilitação neurológica.

Esse encontro não poderia ter sido mais promissor: duas pessoas com interesses comuns pela Educação Somática e trajetórias de dança semelhantes por terem desenvolvido pesquisa em Nova lorque, cidade na qual a dança sofreu grandes influências de uma visão somática de

A autora A, sofreu um AVC em 2007, após anos de formação no ballet clássico e atuação profissional na dança no Brasil e exterior. Estava no primeiro semestre de seu doutorado e desenvolveu sua pesquisa em torno de sua própria experiência para abordar o tema da relaçấo entre dança e deficiência.

Segundo S. Fortin (1999), Educação Somática é a arte e a ciência de um processo relacional interno entre a consciência, o biológico e o meio ambiente, estes três fatores sendo vistos como um todo agente em sinergia'. Fortin, S. em Educaçấo Somática: novo ingrediente da formação prática em dança - Salvador:Cadernos do Cepe-Cit, n 2, p.40-55, 1999 
corpo e que propicia um livre trânsito entre diferentes técnicas e escolas de dança. Ou seja, pessoas com uma formação em dança, parte adquirida numa vivência anterior marcada por vários pontos em comum e que hoje se interessam por abordagens somáticas de trabalho corporal.

O trabalho junto à Companhia Anna Rothlisberger é um contraste em diversos sentidos, como: a escolha do elenco, a determinação das obras a serem apresentadas e a definição do tipo de trabalho corporal a ser utilizado, ao ser comparado às experiências junto a grupos e a grandes companhias de ballet, nas quais existe um cotidiano de trabalho composto de aulas e ensaios para a apresentação de um repertório, que é pré-definido pela direção destas companhias. A escolha das obras a serem criadas e remontadas nestes grupos geralmente independe do elenco que dele faz parte. O tipo de aula ou aquecimento para a preparação corporal do elenco não leva em consideração individualidades dos membros da companhia e muito menos como se sentem, suas emoções ou vontades, mas propõe um esquema pré-formulado e baseado principalmente na técnica de ballet clássico de acordo com aquilo que se conhece como tradicional e usual para este tipo de grupo. Isso ocorre porque as habilidades do elenco são, em geral, similares e a proposta estética dessas companhias de dança já está definida pela direção, a qual é escolhida antes mesmo desta se constituir como companhia.

Já o trabalho junto à companhia de Anna Rothlisberger é um trabalho no qual as diferenças e as individualidades não só são bem-vindas como constituem a base do trabalho, o que está bem de acordo com a visão somática desta diretora. O primeiro teste para participar deste grupo já apontava nesta direção. Diferentemente de experiências no mundo do ballet, não houve uma audição árdua, impessoal e fria. As audições usuais para companhias de ballet são testes nos quais se encontram, às vezes, centenas de bailarinos concorrendo para uma vaga. Os bailarinos são identificados por etiquetas com números e não importa sequer o seu nome. A escolha do elenco nestas audições é feita a partir de características físicas pré-definidas dos indivíduos, como altura, peso, tom de pele, e com base no que conseguem executar tecnicamente, ou seja, baseia-se em suas habilidades técnicas e características físicas.

Na companhia de Anna Rothlisberger, o primeiro teste não foi uma audição, foi uma conversa com a diretora e, posteriormente, Autora A convidada a realizar uma improvisação com outros membros da companhia. Depois de já estar contratada para fazer parte do elenco, Anna confirmou muitas das primeiras impressões causadas: seu interesse é por pessoas, indivíduos e suas personalidades, suas histórias de vida, memórias corporais e não o que seus corpos podem fazer tecnicamente para se expressarem. Ou seja, o que importa é a contribuição que cada indivíduo pode dar como ser humano. Seu interesse maior é no que estas pessoas podem criar em termos de suas ações no espaço e no tempo cênico. A partir destas ações criam-se atmosferas diferenciadas e compostas pelas percepções e sensações dos intérpretes. Assim, propõe-se a pesquisar que universo pode ser composto a partir de cada indivíduo e como estes universos se relacionam ao entrarem em contato uns com os outros. É um processo no qual os participantes são tão diferentes, inclusive do ponto de vista físico e de suas deficiências, que seria impossível o estabelecimento de ideais estéticos de corpo.

Esta diretora já trabalha há algum tempo com pessoas especiais junto a outros bailarinos na sua companhia. Optamos por utilizar o termo especial para denotar pessoas que possuem necessidades físicas especiais, pessoas portadoras de especificidades físicas e que, portanto, não se enquadram em padrões de normalidade física. Evitamos o termo deficiente, por denotar que falta algo a estas pessoas, quando neste caso, é o oposto, pois se trata de bailarinos que, com suas especificidades físicas, acrescentam algo ao trabalho. 
Anos atrás, Rothlisberger realizou uma obra na Espanha com pessoas portadoras de síndrome de Down. A coreógrafa relata os motivos de sua escolha por este trabalho, pois estava cansada da estética reinante na dança contemporânea, presenciando, junto a bailarinos normais, resultados de criação sempre muito parecidos e previsíveis. "Fico fascinada com as soluções de movimento e os universos trazidos por estes bailarinos (especiais)" (informação verbal ${ }^{* * *}$ ), comenta a diretora, que também afirma seu interesse na troca advinda das diferenças físicas e pessoais entre seus bailarinos. Isso ocorre porque as diferenças físicas entre bailarinos especiais proporcionam soluções de movimento e uma expressividade não usuais.

Após este primeiro contato com bailarinos especiais, Rothlisberger optou por incluí-los sempre em seus trabalhos e afirma que é interessante observar a instabilidade física e emocional que a especificidade corporal coloca para o bailarino normal, assim como a estabilidade fornecida pelos bailarinos sem especificidades físicas para os bailarinos com especificidades" Onde inicia a citação? (informação verbal ${ }^{* * *}$ ). É importante notar que a presença destas instabilidades exige que o grupo todo encontre uma fina sintonia de trabalho, na qual se percebe alta doação entre os integrantes e onde todos devem estar presentes, cuidadosamente atentos a cada movimento. Esta doação é uma via de mão dupla, pois aos poucos percebemos que ao lidar com os movimentos na dança, todos os indivíduos encontram eventuais limitações e dificuldades para realizar uma determinada ação.

Isso é comum a todo ser humano. Certa vez, por exemplo, uma das bailarinas havia feito um procedimento dentário e estava impossibilitada de realizar movimentos bruscos com a cabeça. Em outras ocasiões, alguém estava emocionalmente abalado por problemas pessoais ou com uma contratura muscular nas costas por ter realizado uma mudança de moradia no dia anterior. Todos estes estados, nem sempre provenientes de problemas com deficiências físicas, eram levados em consideração e respeitados pelo grupo. É lastimável que estas questões não façam parte da filosofia de trabalho em dança, quando uma visão somática não está presente.

A condição física após o AVC direciona o olhar também para trabalhos de criação que, como o trabalho de Rothlisberger, lidam com dança e limitação física. Diferentes grupos e coreógrafos procuram utilizar a dança como um meio de facilitar a interação entre pessoas com e sem deficiências físicas. Se pensarmos que o autoconhecimento já é difícil para uma pessoa sem limitações físicas, ainda mais para pessoas especiais e na sua integração com pessoas sem limitações físicas. Estes trabalhos, como o de Rothlisberger, são conhecidos por desafiar nossos conceitos e visões sobre dança, assim como sobre a deficiência na sociedade, reconfigurando questões sobre corpo e identidade na vida contemporânea (ALBRIGHT, 1997, p. 58).

A obra de Rothlisberger, assim como outros trabalhos de dança contemporânea que abordam diferenças físicas, permite que ocorra um maior entendimento acerca de como as identidades das pessoas se integram na sociedade e são definidas por meio de seus movimentos corporais. Albright coloca algumas questões interessantes com referência a isto, afirmando que:

Enquanto algumas coreografias contemporâneas chamam a atenção do público para a fisicalidade altamente cinética dos corpos dançantes, minimizando as diferenças culturais entre os bailarinos por enfatizar sua técnica e habilidades físicas em comum para realizar as muitas vezes árduas tarefas de movimento, outras danças evidenciam as marcas sociais de identidade no corpo, usando movimento e texto para comentar (ou frequentemente subverter) os significados culturais destas marcas corporais (ALBRIGHT, 1997, p. 4). 
Brain Game, a mais recente criação de Rothlisberger, é composta por quatro bailarinos: duas bailarinas normais, ou seja, sem nenhuma especificidade física, um bailarino que não possui as duas pernas e Autora $A$, portadora de uma hemiplegia. $O$ mais interessante do trabalho é que ele não gira em torno da questão da especificidade física. É um trabalho que aborda cada indivíduo como um universo particular que traz suas características, experiências e memórias para o trabalho. As especificidades físicas são abordadas apenas como características de cada pessoa, assim como suas personalidades. O cerne do trabalho está na interação resultante do encontro destes universos na cena. É surpreendente defrontar-se com trabalhos como este, no qual o tema da comiseração está ausente; trata-se de bailarinos profissionais que possuem ou não especificidades físicas.

A partir da experiência atual, Autora A percebe a forte ligação existente entre corpo e identidade. Em sua prática cotidiana pode realmente perceber o quanto a maneira como nos movemos interfere em nossa relação com os espaços que habitamos e com as pessoas com as quais dividimos estes espaços. A presença de bailarinos especiais em trabalhos de dança alerta o público para questões referentes a deficiências, que, sejam elas quais forem, afetam a vida de muitas pessoas. Além disso, um corpo jovem com uma deficiência física evidencia ainda mais a realidade que todos enfrentam em relação à finitude material de corpos orgânicos, que inevitavelmente entrarão em decadência. Afinal, a morte, independentemente de tempo ou espaço, é o destino de todos.

Uma obra como esta carrega em si um discurso político e social inerente ao fato de incluir bailarinos com e sem especificidades.

Os princípios políticos, filosóficos e psicológicos fundamentais da cultura ocidental estão baseados em teorias de subjetividade individual e soberania de estado que estão predicados em ideais simplistas de independência e auto-suficiência [...] Ainda acreditamos que o momento primário de autonomia na vida de um indivíduo ocorre quando a criança (ou jovem adulto) torna-se independente de seus pais ou cuidadores... (ALBRIGHT, 1997, p. 61, tradução nossa).

Ao incluir indivíduos que são vistos pela sociedade como pessoas que necessitam de auxílio nas suas atividades de vida diária, trabalhos como o de Anna Rothlisberger não só questionam os ideais de autonomia, independência e auto-suficiência, como também o imaginário com relação a que tipo de movimento pode ser considerado dança e que tipo de corpo pode constituir o corpo de um bailarino ou até um corpo socialmente aceito, visto que a sociedade cria ideais de beleza que são opressivos a todos, em um modelo ideal da pessoa fisicamente perfeita, que não é afetada por fraqueza, perda ou dor.

A pessoa com uma deficiência física em cena não só deixa à mostra o quão tênue é este modelo, este mito do corpo perfeito, como também desafia os ideais de beleza que a dança vem alimentando ao longo de sua história, pois estas pessoas estão longe do belo, do virtuoso e da forma estabelecida como tal principalmente pela estética do ballet. É possível pensar nos sérios problemas causados por questões relacionadas à autoimagem junto à pratica da técnica do ballet como, por exemplo, a anorexia e a bulimia, deficiências que muitas vezes são mais limitadoras do ponto de vista emocional a um bailarino do que uma deficiência física. Infelizmente, a bulimia e a anorexia, como tantos outros problemas, não são facilmente visíveis ou detectáveis em cena. 
Percebe-se que toda a equipe do trabalho, incluindo a diretora, os bailarinos, o músico, 0 dramaturgo, o figurinista, a iluminadora e o artista gráfico, está constantemente questionando e buscando formas de abordagem do tema deficiência de maneira que defina o conceito da obra para nós mesmos e para a sociedade. Somos todos constantemente responsáveis por defender pontos de vista acerca da diferença que cada uma destas especificidades traz. $O$ discurso carregado pelo trabalho ocupa um lugar importante perante o público, a mídia e qualquer indivíduo ou entidade que venha a entrar em contato com a obra.

Feldenkrais (1977, p. 21) critica que "[...] o desenvolvimento da comunicação de massa e as aspirações políticas à uniformidade, também contribuem significativamente para a presente intensificação do obscurecimento das individualidades". A educação, parte constitutiva de nossa autoimagem e de acordo com a qual agimos, "estabelece um padrão de conceitos e reações comuns a uma sociedade específica [...] faz de cada um de nós, membro de alguma sociedade específica e procura fazer-nos tão semelhantes a qualquer outro membro desta sociedade quanto possível" (FELDENKRAIS,1977, p. 19-20). É justamente de encontro a este pensamento massificante que reina em nossa sociedade que Brain Game se posiciona.

Percebemos relações entre o pensamento de Feldenkrais, Rothlisberger e Ziviani no que diz respeito ao trabalho de dança em um grupo. Mesmo que desenvolvendo uma pesquisa com bailarinos normais, Ziviani também procura incentivar a singularidade de cada bailarino, respeitando as diferenças físicas, de formação e de personalidade de cada um. A companhia não realiza audições para contratação de bailarinos. Os bailarinos são convidados a fazerem parte do grupo, geralmente após terem participado, ou mostrado interesse, em atividades relacionadas ao trabalho cotidiano do grupo. Deste modo sua participação e atuação na companhia ocorrem gradativamente possibilitando uma positiva contribuição na dinâmica do todo. Os procedimentos para a criação estimulam e buscam as diferenças de cada um, para que estes possam efetivamente contribuir para a construção do espetáculo. Nas palavras de uma bailarina integrante sobre a companhia:

Percebo que este grupo possui uma característica que o torna singular. Os seus membros se respeitam, cuidam um do outro e mesmo no cargo de diretora, Julia Ziviani compartilha, ensina e estabelece um tipo de relação difícil de explicar com palavras, mas que se percebe em suas atitudes e palavras conosco. Fruto, acredito eu, de uma extensa experiência com os métodos somáticos, que ensinam não apenas modos diferentes de organização do corpo, mas também maneiras de relacionar-se consigo mesmo e com o outro. (BAILARINAA)

Na companhia de Anna Rothlisberger o processo de trabalho para a criação e estreia da obra Brain Game foi interessante e enriquecedor. A preparação corporal do elenco durante o processo de criação foi realizada por meio de sessões diárias de Feldenkrais. A aplicação do Método de Feldenkrais pode ser feita de duas formas: através de sessões em grupo e do trabalho individual na Integração Funcional. No trabalho coletivo o instrutor indica as seqüências de movimentos a serem realizadas, por cada participante, através da palavra. Já a Integração Funcional pressupõe que exista uma relação atuante entre o instrutor e o indivíduo, pois além da palavra o instrutor utiliza também o toque para orientar a movimentação do aluno. (WOLFF, 2010), que é feito numa sessão fechada entre instrutor e indivíduo.

O uso diário de propostas advindas de Feldenkrais, neste caso em processos coletivos, incentivava uma procura criativa sobre modos de se realizar uma tarefa. $O$ respeito ao corpo e às individualidades de cada um era sempre pontuado e vinha em primeiro lugar. Cada gesto, 
movimento ou proposta de exercício era colocada não como um ideal a ser atingido ou conquistado, mas como algo que deveria facilitar a ação e, portanto, deveria estar a serviço de cada bailarino, o que permitia que fosse executado de maneiras diferentes e com a melhor possibilidade por cada um. Claro que não poderia ser de outra forma, tratando-se de um grupo no qual um elemento não possui as pernas e outro apresenta uma hemiplegia. Acreditamos, entretanto, que as propostas de Feldenkrais, também realizadas pelo elenco sem especificidades físicas, favoreceram uma resposta criativa enriquecedora.

A partir da vivência acima, pensamos que seria interessante que esta mentalidade respeitosa ao indivíduo pudesse permear o ensino da dança através da técnica do ballet ou de qualquer outra técnica de dança. Será possível pensar o ensino da dança a partir de uma proposta mais somática? Ainda que esta visão tenha que se adequar aos objetivos do uso de uma técnica e possa variar em intensidade de acordo com cada contexto. A partir de nossa vivência em aulas de ballet junto ao Departamento de Dança da New York University, e conhecendo diversos professores na cidade de Nova lorque que se propõem a ministrar "aulas de ballet para bailarinos contemporâneos" (WOLFF, 2010), sabemos que esta abordagem diferenciada e mais somática da técnica do ballet é possível, talvez apenas não tão abrangente e disseminada quanto seria predominantemente benéfica. Os exemplos aqui citados tratam de usos desta técnica para a performance em dança contemporânea. Entretanto, questionamos: o pensamento diferenciado que a visão somática traz do movimento e do indivíduo, não poderia ser aplicado também na prática e ensino da técnica de ballet para formação de bailarinos que executarão obras do repertório clássico? A específica formação de bailarinos clássicos visando à performance de repertório clássico tradicional também nos parece relevante e merecedora de estudos sobre como as habilidades corporais exigidas destes bailarinos podem ser adquiridas com as contribuições somáticas e de que modo isto influenciaria no seu treinamento cotidiano.

Entendemos cada vez mais o quanto pode ser positiva uma abordagem somática na dança. No trabalho diário junto à Companhia Rothlisberger, vimos que quando estava todo o elenco presente havia uma maior flexibilidade interna na busca pelo possível, no sentido de se buscar a melhor resposta dentro das possibilidades de cada um e não um pressuposto ideal como aquele presente em uma formação no ballet. Em algumas circunstâncias, ocorreu de James O'Shea, o bailarino sem as pernas, não poder estar presente no aquecimento. Nestes dias, em meio a um grupo de pessoas todas sem especificidades, era possível observar em Autora A o afloramento de resistências internas ancoradas em ideais estéticos e funcionais. Isso provavelmente é resultante de uma exposição principalmente à técnica de ballet ensinada sem a aplicação dos princípios somáticos, pois notamos que esta formação deixou marcas na organização do corpo construída por meio de padrões inadequados de movimento, como também na maneira de pensar sobre o movimento. Percebemos, também, que com amigos e conhecidos fora do cotidiano da companhia, Autora A frequentemente mencionava situações de trabalho que incluíam James e não as outras bailarinas. Isso nos faz pensar que ocorria uma identificação maior sua com este bailarino, também portador de uma especificidade física.

No cotidiano da companhia, após a preparação corporal do elenco, que estava bastante baseada no trabalho corporal proposto por Feldenkrais, passávamos ao processo de criação. Anna Rothlisberger pedia: "[...] sempre traga sua personalidade ao trabalho, é nisto que estou interessada... Encontre a sensação correta para cada cena" (informação verbal ${ }^{* * * *}$ ). Nesta fala da diretora, percebemos a definição de Feldenkrais (1977, p. 27) que afirma: "[...] nossa autoimagem consiste de quatro componentes que estão sempre envolvidos em toda a ação: 
sensação, sentimento, movimento e pensamento", o que, ao ser percebido, pode levar a uma presença cênica plena. Uma presença que, para Rothlisberger, era válida quando havia uma compreensão da cena por cada intérprete e deste em relação com o grupo. Para ela, era necessário que todo movimento ou ação cênica viesse acompanhado de sensação, sentimento e pensamento. Rothlisberger acrescenta: "[...] isto é mais importante do que qualquer técnica que permita que você execute algum movimento" (informação verbal ${ }^{* * * * *}$ ). As orientações que recebíamos nos colocavam em contato com o que percebíamos internamente, ligando a ação à autoimagem e trazendo à tona a personalidade de cada um. Como em outros trabalhos dos quais Autora A participou, Rothlisberger também partia de improvisações, incentivando bastante que o elenco trouxesse suas memórias e propusesse temas, textos, objetos ou figurinos pertinentes. Isso era possível porque este processo de criação voltava-os para as imagens, pensamentos e sensações próprias, permitindo que tivessem liberdade e autonomia para encontrar a melhor solução para cada cena.

Como parte da herança de Autora A da dança, frequentemente aparecia algum elemento da técnica do ballet em suas improvisações, o que aponta para uma predominância desta técnica no seu corpo. É interessante observar que "cada um de nós fala, se move, pensa e sente de modos diferentes, de acordo com a autoimagem que tenha construído de si mesmo com o passar dos anos" (FELDENKRAIS, 1977, p. 27). Feldenkrais acrescenta ainda que a autoimagem se desenvolve a partir de ações e reações no curso normal da experiência (lbidem, p. 19). Considerando a estreita relação entre ação e autoimagem, é possível perceber a influência que uma formação no ballet pode ter sobre a autoimagem do indivíduo. No entanto, estes elementos surgidos nas improvisações, reconhecidos como do vocabulário do ballet, eram sempre bem-vindos e incluídos no trabalho, pois são parte de quem Autora A é e constituem sua identidade corporal. Certa vez Autora A escutou a seguinte observação de Rothlisberger: "gosto muito desta sua presença delicada e nobre". É claro que questionamos de onde vem esta presença. Será que Autora A ainda carrega no corpo esta imagem nobre e delicada do ballet? Acreditamos que a ênfase no uso da verticalidade do ballet reforçado pelo seu biótipo longilíneo e elegante são características que aparecem frequentemente, remetendo a esta imagem nobre, bela e contida.

Dessas improvisações surgiu uma parte de um solo em que são realizados movimentos similares aos realizados por bailarinas interpretando cisnes, em obras do repertório da dança clássica como O Lago dos Cisnes e A Morte do Cisne, as quais acompanham a história performática de Autora A já há bastante tempo. Como elas poderiam fazer-se ausentes? Certa vez a diretora fez uma afirmação que chamou a atenção da intérprete criadora e que colocamos aqui, porque carrega uma série de questões sobre as quais já refletimos: "[...] o teu braço é como algo advindo de um museu ${ }^{* * * * * * \prime \prime}$. Esta menção a museu, neste caso, remete à ideia de sagrado, algo consagrado ao culto, portanto, venerável, respeitável, inviolável ou religioso.

A sensação de estar em um museu ou em um local sagrado é algo que Autora A experimentou novamente ao entrar no teatro para ensaiar na semana anterior à estreia. Mais uma vez, a presença de flores, o cheiro de produtos de maquiagem e para cabelos, a troca de presentes e chocolates no dia da estréia trouxe recordações de outro tempo e espaço, aquele pertencente ao mundo do ballet. Durante o espetáculo, ao realizar o solo, ser vista por e ver o público, percebeu que o silêncio que se instaurava na plateia durante a performance era um silêncio respeitoso, como aquele sentido nas espaçosas e imponentes igrejas.

\footnotetext{
******* Ibidem.

******* Comentário feito por Anna Rothlisberger, no Roxy Theater, na Basileia, entre 28 de janeiro e 04 de fevereiro de 2010.
} 
Mais uma vez Autora A presenciou o eventual comentário, percebido ao longo de sua formação em dança clássica, referente à beleza: "[...] vocês estão tão lindos em cena, como vocês são bonitos, todos vocês" (informação verbal ${ }^{* * * * * * *}$ ), dizia a diretora após cada espetáculo. Realmente, a experiência do belo sempre acompanha a experiência da dança. Neste caso, entretanto, preferimos pensar que a beleza refere-se aos indivíduos envolvidos no trabalho, beleza que se constrói de dentro e não em um ideal estético de corpo pré-definido por alguma técnica de dança. Propomos que se pense beleza na dança a partir da definição utilizada na obra $O$ que é beleza, onde o substantivo estética

[...] designa hoje qualquer conjunto de ideias (filosóficas) com o qual se procede uma análise, investigação ou especulação a respeito da arte e da beleza. Estética é a ciência da beleza. Por beleza, entenda-se uma maneira de nos relacionarmos com o mundo: não diz respeito às qualidades dos objetos (ou manifestações artísticas), mensuráveis, quantificáveis e normatizáveis, diz respeito à forma como nos relacionamos com eles. Beleza é relação (entre sujeito e objeto). (DUARTE JÚNIOR, 1991, p. 8, 14).

Após a temporada de Brain Game, colhemos os frutos. Do ponto de vista pessoal, o enriquecimento foi imenso. Ao final da temporada, realizada na Basileia, Autora $A$ percebeu que estava de volta ao circuito profissional e independente de dança. Mais do que isso, estava inserida no mercado da dança contemporânea europeia. É quase irônico pensar que, por muito tempo, seu objetivo tenha sido dançar em uma companhia de ballet da Europa. Já em outros tempos o objetivo era tornar-se uma bailarina contemporânea. Em ambas as circunstâncias, distintos aspectos surgiram como empecilhos para que estes objetivos fossem conquistados. No Brasil, talvez fosse muito clássica para ocupar espaços contemporâneos. Na Europa, talvez não fosse clássica o suficiente para atender às exigências estéticas e técnicas de uma companhia de ballet. Atualmente, colhe os frutos de um caminho intenso e tortuoso. Ocorre que a mesma especificidade física que a excluiu do mundo do ballet acabou servindo como fator de sua inclusão na dança contemporânea. Satisfaz-lhe perceber que foi membro de uma companhia de dança contemporânea suíça, onde trabalham juntos bailarinos com e sem deficiências físicas e cuja base do trabalho é o método de Educação Somática criado por Moshe Feldenkrais.

Entretanto, acreditamos que o que foi mais rico na participação deste trabalho tenha sido a troca de experiência de vida e corporal com as pessoas envolvidas. Algo que geralmente não ocorre em trabalhos de caráter mais clássico ou tradicional. Será que o distanciamento proposto pelo ballet clássico, inclusive do ponto de vista da forma como os corpos são trabalhados no espaço, tem a ver com isto?

Após a temporada, Autora A teve ainda a sorte de encontrar um mestre de Feldenkrais, que encontrava-se na Basileia para um evento relacionado a este método. Paul Rubin é um instrutor senior de Feldenkrais atuante no Canadá e Estados Unidos. Uma pessoa inteligentíssima, experiente e extremamente generosa, que se colocou à disposição para uma sessão individual. $O$ encontro foi muito frutífero e despertou uma curiosidade e um interesse maiores ainda por este método. Foram discutidos muitos temas relacionados à dança, ao emprego da técnica do ballet na formação em dança, e assuntos de interesse atual das autoras como Educação Somática, e os métodos Feldenkrais, Alexander, Ideokinesis, neurologia, enfim, os possíveis intercâmbios entre a arte e a ciência. Depois desta conversa inicial, passaram à etapa do trabalho que se chama Integração Funcional. 
Em uma atmosfera mais quieta e silenciosa, Autora A observou os estímulos e as manipulações realizadas por Rubin. Ficou atenta aos seus próprios movimentos e respostas. Percebeu em diversos momentos uma vontade interna de responder, controlar ou manipular ativamente suas respostas corporais. Optou por comentar estes ímpetos com Rubin e recebeu respostas verbais que nos parecem relevantes e válidas para se mencionar aqui. Rubin comentou que suas experiências com bailarinos, em geral, demonstram que eles são sempre muito ativos e apresentam respostas físicas bastante acima da necessária para a situação, provavelmente por estarem acostumados e terem sido exigidos em sua educação na dança a sempre mostrar algum resultado, realizar os movimentos e produzir algo bem elaborado. No caso específico de bailarinos clássicos, esta atividade ainda vem acompanhada de uma busca obsessiva por controle qualitativo e quantitativo da performance corporal durante as respostas.

Paul Rubin apresentou uma expressão que acreditamos seja precisa e aplicável a diversos contextos: diplomacia neurológica, utilizado por ele para se referir a algum ajuste corporal que Autora A tenha feito para acomodar melhor os seus estímulos. Utilizamos aqui um conceito proveniente da Ideokinesis que acreditamos pode auxiliar na compreensão desta expressão. A partir da Ideokinesis, pode-se definir movimento "[...] como um evento neuromusculoesquelético [...] e para que movimento voluntário ocorra é necessário que estes três sistemas do corpo estejam envolvidos: o sistema muscular, o nervoso e o esquelético" (BERNARD, 2006, p. 45). 0 sistema nervoso é o mensageiro, o muscular é o cavalo de força que faz o trabalho e o sistema esquelético é o sistema de suporte que é movido. Em nossa experiência de corpo atual, diplomacia neurológica refere-se a uma certa negociação entre o sistema nervoso e o indivíduo, acompanhado de sua fisicalidade para encontrar soluções de movimentos que, ao mesmo tempo, em que exigem uma reorganização funcional do sistema nervoso possam fornecer algum conforto ou uma segurança interna. É dentro desta premissa que propomos a realização de processos educacionais inteligentes e produtivos em dança, que utilizem a sensação e a percepção do início, percurso e finalização dos movimento em pequenos gestos ou sequências coreográficas, seja a partir da técnica do ballet ou de qualquer outra técnica de dança.

\section{Referências}

BERNARD, André. Ideokinesis: a criative aproach to human movement and body alignment. Berkeley: North Atlantic, 2006.

ALBRIGHT, Ann Cooper, Choreographing Difference: The Body and Identity in Contemporary Dance. Hanover, NH: University Press of New England, 1997.

DUARTE JÚNIOR, João Francisco. O Que é Beleza. São Paulo: Brasiliense, 1991.

FELDENKRAIS, Moshe. Consciência pelo movimento. São Paulo: Summus Editorial, 1977.

FORTIN, Sylvie. Educação somática: novo ingrediente da formação pratica em dança. Cadernos do Gipe-cit, n. 2, p. 40-55, nov. 1998.

SWEIGARD, Lulu. Human Movement Potential: its idiokinetic facilitation. Berkeley: North Atlantic Books, 1974.

TODD, Mabel E. The Thinking Body. New York: Dance Horizons, 1937.

WOLFF, Silvia S. Momento de transição: em busca de uma nova eu-dança. $110 \mathrm{f}$. Tese (doutorado em Artes). Universidade Estadual de Campinas, Canpinas, São Paulo, 2010. 